\title{
Large Strain Actuation in Polypyrrole Actuators
}

\author{
Patrick A. Anquetil ${ }^{* a}$, Derek Rinderknecht ${ }^{a}$, \\ Nathan A. Vandesteeg ${ }^{\mathrm{a}}$, John D. Madden ${ }^{\mathrm{b}}$ and Ian W. Hunter ${ }^{\mathrm{a}}$ \\ ${ }^{a}$ BioInstrumentation Laboratory, Dept. of Mechanical Engineering; Massachusetts Institute of \\ Technology, 77 Massachusetts Ave., Cambridge, MA, 02139, USA \\ ${ }^{\mathrm{b}}$ Dept. of Electrical and Computer Engineering, The University of British Columbia, \\ 2356 Main Mall, Vancouver, BC Canada V6T 1Z4
}

\begin{abstract}
A typical limitation of polypyrrole based conducting polymer actuators is the low achievable active linear strains ( $2 \%$ recoverable at $10 \mathrm{MPa}, 7 \% \max$ ) that these active materials exhibit when activated in a common propylene carbonate / tetraethylammonium hexafluorophosphate electrolyte. Mammalian skeletal muscle, on the other hand, exhibits large recoverable linear strains on the order of $20 \%$. Such large linear strains are desirable for applications in life-like robotics, artificial prostheses or medical devices. We report herein the measurement of recoverable linear strains in excess of $14 \%$ at $2.5 \mathrm{MPa}(20 \% \max )$ for polypyrrole activated in the 1-butyl-3-methyl imidazolium tetrafluoroborate liquid salt electrolyte. This advancement in conducting polymer actuator technology will impact many engineering fields, where a lightweight, large displacement actuator is needed. Benefits and trade offs of utilizing ionic liquid electrolytes for higher performance polypyrrole actuation are discussed.
\end{abstract}

Keywords: Polypyrrole, ionic liquid, imidazolium, large strain, characterization.

\section{INTRODUCTION}

Polypyrrole-based conducting polymer actuators are becoming a mature technology, leaving the lab bench to be incorporated into actual products ${ }^{1,2,3,4}$. Recent studies have revealed that polymer actuators can exhibit very high active stresses (40 MPa peak) and moderate contractile linear strains ( 2\% to $7 \%$ at $10 \mathrm{MPa}, 12 \%$ for corrugated electrodes ${ }^{5}$ ) and speeds (3 to $12 \% / \mathrm{s})^{6}$, with high power to mass ratios $(150 \mathrm{~W} / \mathrm{kg})$, cycle life exceeding the million cycles while being activated at low electrical voltages $(\sim 1 \text { to } 5 \mathrm{~V})^{7}$. Such polymeric contractile materials would be perfectly suited to power medical devices, small robots as well as innovative consumables and toys. However despite all these successes, the strain and speed at which these contractile materials are behaving is still not enough for such applications and for the replacement of small motors.

On the other hand if we look across nature, mammalian skeletal muscle exhibits similar power densities (50 to 100 $\mathrm{W} / \mathrm{kg}$ ), but the picture is reversed. Namely, mammalian skeletal muscle produces much higher strains in-situ (20\%) at lower stresses $(0.5 \mathrm{kPa})$ and at higher rates $(100 \% / \mathrm{s})^{8}$. Large strains are greatly desirable as they enhance the working space in which a robot interacts or the degree of function that a device can perform. No conducting polymer material exists to date that matches or exceeds mammalian skeletal muscle in terms of high linear strains at high stresses ${ }^{8}$. In this paper we present an enhancement of conducting polymers actuators by using room temperature ionic liquids as electrolyte $^{1}$. Use of imidazolium-based ionic liquid such as 1-buthyl-3-methyl imidazolium tetrafluoroborate or hexafluorophosphate leads to surprising high strains (14.5\% recoverable, 20\% max.) at moderate stresses (2.5 MPa) while improving cycle life at the same time.

\footnotetext{
*Correspondance: patanq@ mit.edu, http://bioinstrumentation.mit.edu
} 


\section{OPTIMIZATION OF POLYPYRROLE: A SYSTEMS APPROACH}

Three different approaches exist to enhance the strain production of conducting polymer actuators. The first approach involves the creation of radically new conducting polymer molecules designed from the bottom up for specific actuation properties (load bearing, large strain, stability, ...). This field is being pioneered by our group and others ${ }^{6,10,11,12}$. The second option is to convert the high force that conducting polymers such as polypyrrole can produce into higher strains via mechanical advantage. This can be achieved either by creating a mechanical lever structure or by shaping the material into a bi- or tri-morph configuration ${ }^{13}$. Finally, the third approach, pioneered by Madden and Wallace ${ }^{7,14,15}$ is to look at polypyrrole actuators as an electrochemical system and to optimize it. The conducting polymer actuator electrochemical system comprises:

- A polymer working electrode

- A counter electrode

- An electrolyte

\section{Optimization of the working and electrodes}

Actuation in traditional conducting polymer actuators such as polypyrroles is driven by a mechanism of ion intercalation, leading to moderate strains ${ }^{16,17}$. Improvements in the polymer (actuator) working electrode to achieve higher strain rates involves the use of multiple charge injection points, corrugated electrodes ${ }^{5}$ and thinner films ${ }^{14}$. The first two methods allow faster channeling of electrons into the polymer electrode, while the later one allows faster diffusion of ionic species into the material, leading to faster full charging of the material. The efficiency of the counter electrode can be increased by employing a conducting polymer electrode, allowing for higher charge storage at the counter electrode.

\section{Optimization of the electrolyte}

Typical actuation limitations such as achievable strain, strain-rate and ultimately cycle degradation results from electrochemical material degradation due to the application of an excessively large potential to the material. The measure of the degree of actuator electrochemical robustness is assessed by the so-called electrolyte and polymer potential window. For PPy in propylene carbonate, for example, the typical maximal potential applicable without degradation is about $0.4 \mathrm{~V}$. Recent studies by $\mathrm{Lu}$ and al. ${ }^{1}$ show that the electrochemical potential of PPy can be extended to $4 \mathrm{~V}$ by using ionic liquids comprising 1-butyl-3-methyl imidazolium cations (Figure 1). A system with a large potential window potentially translates into faster actuator performance and enhanced cycle life. In addition maximum strain can be increased as presented in this paper.

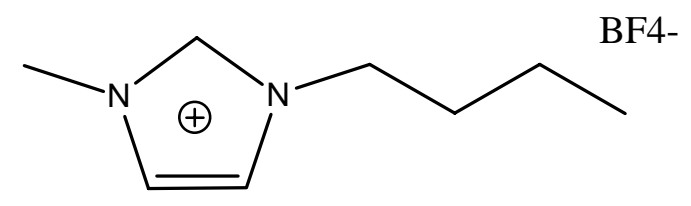

Figure 1: Structure of the 1-butyl-3-methyl imidazolium tetrafluoroborate ionic liquid (BIMI-BF4).

\section{EXPERIMENTAL}

\subsection{Reagents}

Pyrrole monomer (Py), tetraethylammonium hexafluorophosphate (TEAP) and propylene carbonate (PC) were obtained from Aldrich (www.aldrich.com). Ionic liquid such as 1-butyl-3-methyl imidazolium tetrafluoroborate was purchased from Solvent Innovation, GMBH (www.solvent-innovation.com). Silver reference electrodes were constructed from the BAS Bioanalytical Systems (www.bioanalytical.com) reference electrode kit. 


\subsection{Preparation of polymers}

Synthesis was performed by electrodeposition under galvanostatic condition onto a conducting glassy carbon substrate (Alfa Aesar, www.alfa.com) and the counter electrode was a copper sheet (Aldrich, www.aldrich.com). Conducting polymer films were grown from a solution of freshly distilled $0.05 \mathrm{M}$ pyrrole (Py) monomer, $0.05 \mathrm{M}$ TEAP and $1 \% / \mathrm{vol}$ water, following the method of Yamaura ${ }^{18}$. Galvanostatic depositions were conducted at current densities of $1.25 \mathrm{~A} / \mathrm{m}^{2}$ for 8 to 16 hours resulting in film thickness between 10 and $30 \mu \mathrm{m}$. Deposition took place at low temperature $\left(-40^{\circ} \mathrm{C}\right)$. The resulting films of polypyrrole were then peeled off the working electrode substrate, rinsed in acetonitrile and conserved in a $0.1 \mathrm{M}$ TEAP in propylene carbonate solution. Polypyrrole films had an average conductivity of $4.5 \times 10^{4}$ $\mathrm{S} \cdot \mathrm{m}^{-1}$, densities between 1300 and $1600 \mathrm{~kg} \cdot \mathrm{m}^{-3}$, tensile strengths of $26 \mathrm{MPa}$ and Elastic moduli of $0.38 \mathrm{GPa}$ while immersed in propylene carbonate.

\subsection{Techniques and instrumentation}

Electrodepositions and electroactivations were carried out with a potentiostat (Amel, Model 2049, www.amelsrl.com). Bulk conductivity measurements were conducted on a custom built four point measurement apparatus connected to a multimeter (Keithley, model 2001, www.keithley.com). Passive mechanical testing of the polypyrrole samples were conducted using a Perkin Elmer Dynamic Mechanical Analyzer (DMA 7e) (instruments.perkinelmer.com). It allows tensile tests to be performed on polymer films in or out of solution and at a controlled temperature. This apparatus was used to study the response of polypyrrole as a function stress

Active testing of polypyrrole was performed by an in-house-designed scientific instrument. No commercial tensile testing device exists that adequately combines mechanical testing with electrochemical excitation and monitoring. As a result, we designed and constructed an electrochemical Dynamic Mechanical Analyzer (DMA) testing apparatus for performing isometric (constant length), isotonic (constant force) and high frequency stress-strain measurements.

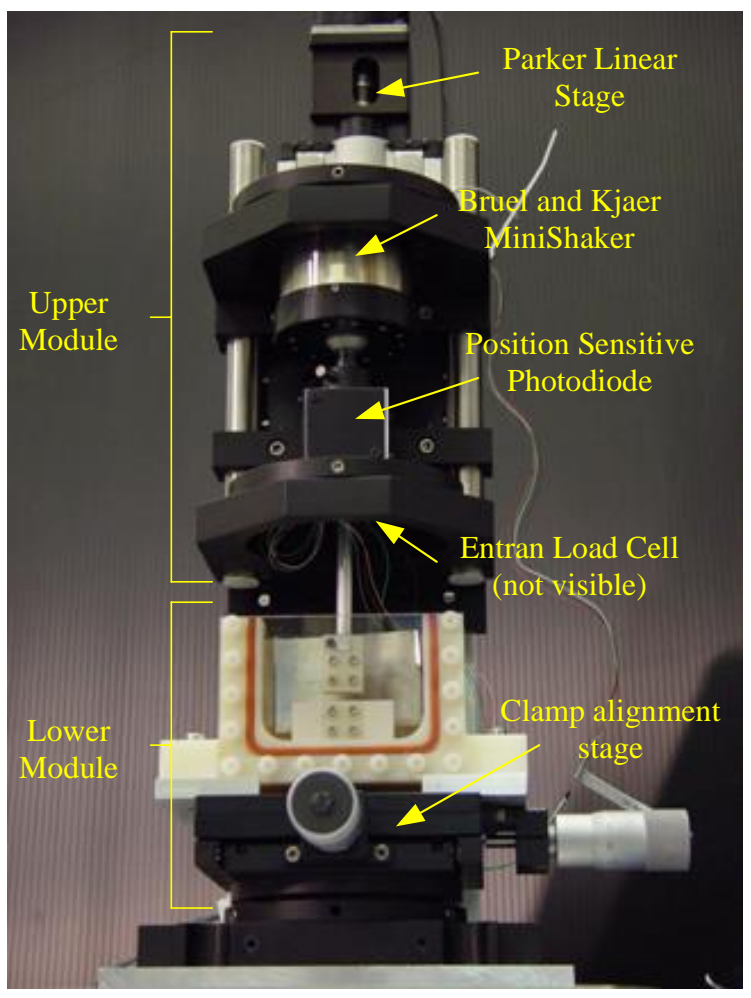

Figure 2: Electrochemical DMA developed to study the active linear strain of conducting polymer actuators. 
This custom made instrument is composed of two modules. The top half comprises force and displacement sensors as well as actuators, all connected to the upper sample clamp and probe. The bottom half module hosts the lower sample clamp and electrochemical bath. A picture of our DMA is presented in Figure 2. Thin film samples are held vertically between two clamps within an electrochemical bath. Force is applied to the sample via a voice coil actuator (Bruel and Kjaer minishaker Model 4810, www.bkhome.com). An aluminum rod connects the voice coil actuator to the upper clamp. In series with the clamp is a load cell, allowing recording of the applied force (GS Sensors 10N load cell www.gssensors.com, with Vishay 2311 Signal Conditioning Amplifier www.vishay.com). An LED placed along the rod provides a light source for a position sensitive photodiode, thereby enabling position measurement (Pacific Silicon Sensors, www.pacific-sensors.com, PSS-DL100-7PCBA duolateral (2-axis) position sensing module, with PSS-DL-100 position sensing photodiode (PSD)). The applied force is under computer control via a data acquisition board (Allios 16bit A/D, D/A, $50 \mathrm{kHz}$ sampling http://bioinstrumentation.mit.edu) and a voltage to current amplifier. A graphical user interface designed in Visual Basic 6.0 (www.microsoft.com) includes a digital control algorithm for maintaining a desired force based on the force output measured by the load cell. Vertical sample positioning can be achieved via a stepper motor and linear stage (Parker linear stage with a Zeta57-51-MO stepper motor and a Compumotor Zeta 6104 Indexer Drive connected to the RS-232 port, www.compumotor.com), while horizontal alignment is achieved via a micrometer driven stage.

With this electrochemical DMA, stress-strain tests can be performed at various strain rates, with a bandwidth of $100 \mathrm{~Hz}$. The minimal resolvable displacement and force are $1 \mu \mathrm{m}$ and $1 \mathrm{mN}$ respectively, while the maximum measurable displacement is $3 \mathrm{~mm}$ and the maximum applicable force is $10 \mathrm{~N}$. In addition, this apparatus enables electrochemical potential or current to be digitally controlled, thereby allowing active stress and active strain to be monitored as a function material oxidation state.

\section{CHARACTERIZATON OF POLYPYRROLE ACTUATORS}

The actuators presented herein are intended to be incorporated into devices and achieve active functions. Therefore, understanding and characterizing their mechanical properties, both active and passive is very important. Passive properties show how well the material can hold a given, load. These passive properties comprise Young's modulus, the tensile strength and elongation to break. The active properties represent the active performance of the material. These include active stress, active strain and active strain rate. Both the passive and active mechanical properties characterize the actuator material in the mechanical domain. Further properties relevant to actuation include electrical conductivity and density.

\subsection{Passive Mechanical properties}

PPy films (12 mm long, $2 \mathrm{~mm}$ wide, $20 \mathrm{~mm}$ thick) were clamped into a Perkin Elmer 7e Dynamic Mechanical Analyzer and stretched at a rate of $83.3 \mathrm{kPa} / \mathrm{s}$ while being immersed in propylene carbonate containing $0.1 \mathrm{M}$ tetraethylammonium hexafluorophosphate (0.1 M TEAP in PC). Notice that the polypyrrole film was immersed in $0.1 \mathrm{M}$ TEAP in propylene carbonate for the entire length of the test. Figure 3 shows the mechanical response of a typical polypyrrole sample as a function of applied stress. The tensile strength is $26 \mathrm{MPa}$ at an elongation to break of $15 \%$ and the elastic modulus of the film $\mathrm{E}_{\text {young }}=0.38 \mathrm{GPa}$, which is standard for polypyrrole thin films. 


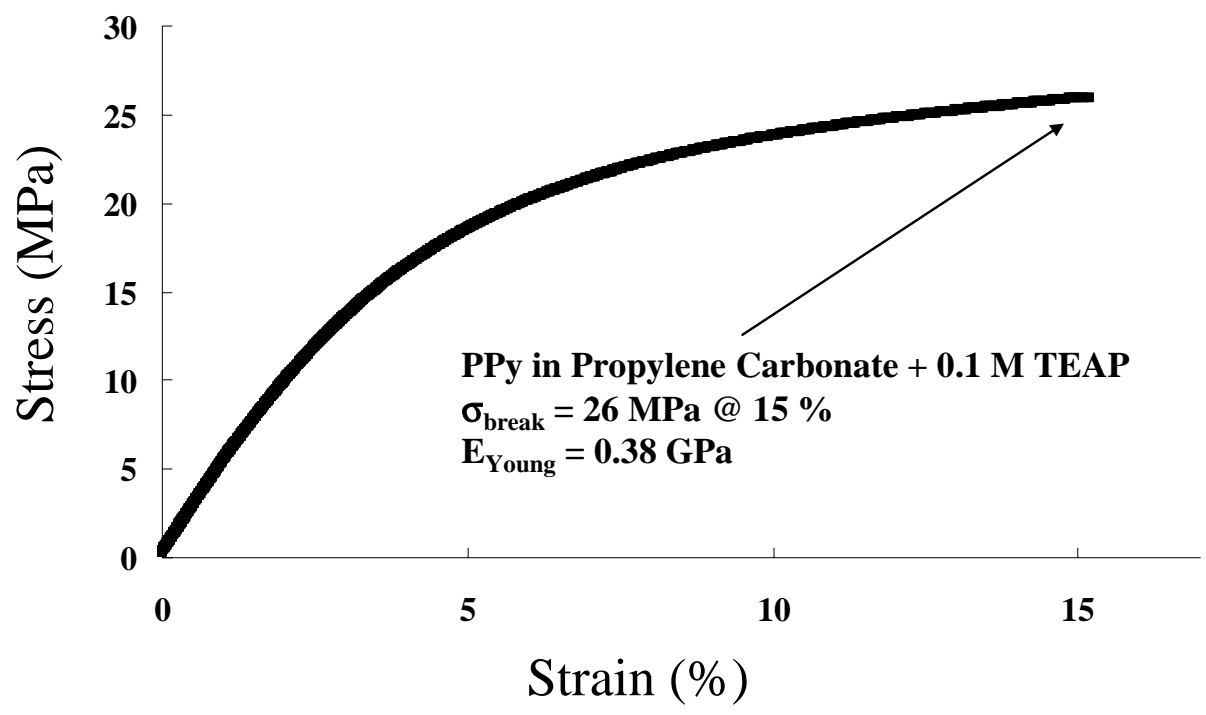

Figure 3: Mechanical response of PPy immersed in 0.1 M TEAP in PC.

\subsection{Low frequency isometric actuator testing}

Actuation of polypyrrole actuators into a liquid salt electrolyte leads to surprising active behavior. Our initial results show recoverable large strains of $14.5 \%$ (20\% max. strain) for polypyrrole in 1-butyl-3-methyl imidazolium tetrafluoroborate (BMIM-BF4 ) under isotonic conditions (2.5 MPa). Measurements of active mechanical properties are made under constant strain (isometric). Current and voltage are applied to the electroactive material and recorded under digital control using our electrochemical DMA, thereby allowing contractile properties to be related to charge transfer.

A sample of polypyrrole ( $6 \mathrm{~mm}$ long, $2 \mathrm{~mm}$ wide, $10 \mu \mathrm{m}$ thick) was attached between two nylon clamps containing stainless steel electrical contacts and held at constant 2.5 MPa initial load and immersed in BMIM-BF4 electrolyte. The electrochemical cell circuit was composed of the polymer sample and a stainless steel counter electrode. A sawtooth potential was applied to the film and monitored via a silver wire pseudo-reference electrode. This potential was varied between $1.7 \mathrm{~V}$ and $-0.8 \mathrm{~V}$ versus the silver wire pseudo-reference electrode. Note that the Open Circuit Potential of the polypyrrole electrode (OCP) was $0.443 \mathrm{~V}$ versus the silver wire and that the actual potential input was therefore varied by $\pm 1.25 \mathrm{~V}$ versus $\mathrm{OCP}^{1}$. In this particular test, the activation frequency was $0.01 \mathrm{~Hz}(100 \mathrm{~s}$ per cycle). The input potential, charge response and resulting active strain of the polypyrrole actuator in BMIM-BF4 are presented in Figure 4.

With regards to Figure 4 we notice several unusual features:

- An initial active strain of $20 \%$

- An overall creep of $20 \%$ after 5 cycles that is reduced to $3 \%$ per cycle after the $3^{\text {rd }}$ cycle

- A recoverable strain of $14.5 \%$ (contraction) produced against the average creep at each cycle.

- Charge flowing in the film is opposite sign from the measured active linear strain, suggesting that the imidazolium cation and not the small $\mathrm{BF}^{-}$is diffusing into the polymer

- A charge amplitude of $0.42 \mathrm{C}$

- A strain to charge ratio of $1.37 \times 10^{-10} \mathrm{~m}^{3} / \mathrm{C}$. Notice that this value of the strain to charge compares with the typical quoted values for PPy actuated in $0.1 \mathrm{M}$ TEAP in propylene carbonate: $1.3 \pm 0.3 \times 10^{-10} \mathrm{~m}^{3} / \mathrm{C}^{19}$

\footnotetext{
${ }^{1}$ The OCP is an indication of the initial state of the film before it is activated. Note that it only represents a temporary electrochemical equilibrium that is a function of the history of the film.
} 

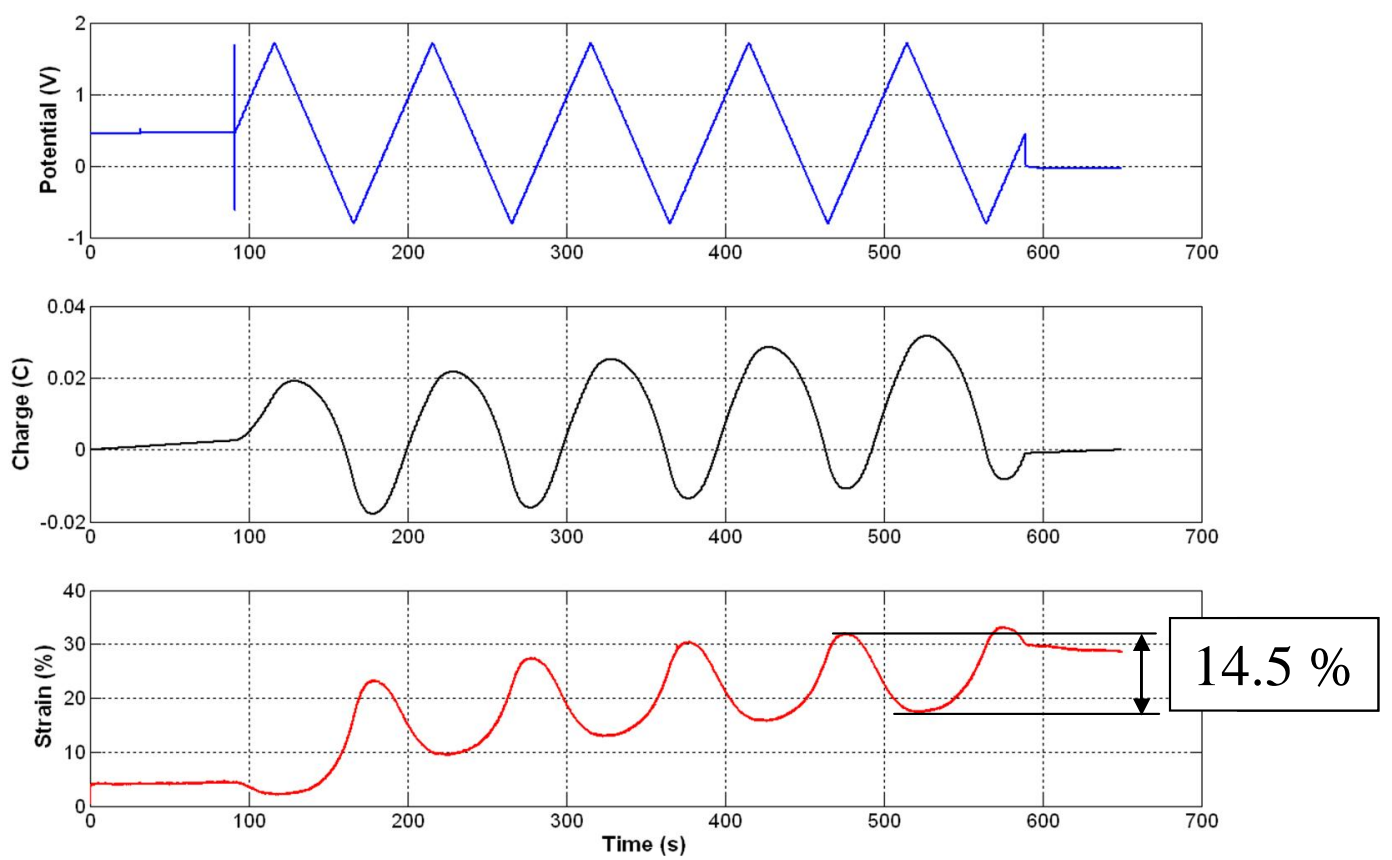

Figure 4: $14.5 \%$ recoverable strain (20\% maximum) in polypyrrole actuators activated in BMIM-BF4

This result is the first demonstration that linear strains in excess of $14.5 \%$ can be recovered by a polypyrrole conducting polymer actuator against a load of $2.5 \mathrm{MPa}$. However, these large strains are accompanied by a large creep, resulting in an average unrecoverable extension of the film of $3 \%$ per cycle after the 3rd cycle of activation. In addition the speed of actuation for this $10 \mu \mathrm{m}$ film is quite slow: $0.36 \% / \mathrm{s}$ (compared with $3 \% / \mathrm{s}$ for PPy activated in $0.1 \mathrm{M}$ TEAP in PC at $5 \mathrm{MPa}$ ). Based on the charge to strain relationship, we estimate that the BMIM cation is diffusing into the polymer. The larger size of the BMIM cation compared to PF6 could explain why the speed of contraction is decreased from a typical value of 3\%/s achieved for PPy activated in $0.1 \mathrm{M}$ TEAP in PC. The ionic liquid-based activation results of polypyrrole are compared to our PF6 ${ }^{-}$actuator benchmark as well as to human skeletal muscle in Table 1.

In subsequent tests we increased the activation frequency to $1 \mathrm{~Hz}(1 \mathrm{~s}$ activation cycle) and measured the resulting strain and cycle life. A different polypyrrole film (6 mm long, $2 \mathrm{~mm}$ wide, $10 \mu \mathrm{m}$ thick) was held at $2.5 \mathrm{MPa}$ and activated between $+4.5 \mathrm{~V}$ and $-4.0 \mathrm{~V}$ versus silver pseudo-reference electrode. We measured a cycle life in excess of 100,000 cycles at $0.5 \%$ linear strain, $2.5 \mathrm{MPa}$ stress and $1 \mathrm{~Hz}$ cycle frequency for PPy activated in BMIM-BF4 ionic liquid. No degradation and no decrease of linear strain amplitude was observed after conducting a 100,000 cycle test as previously observed by Wallace ${ }^{1}$. Further test will determine the maximum cycle life attainable by Polypyrrole when activated in BMIM-BF4 ionic liquid. 


\begin{tabular}{|l|c|c|c|}
\hline \multicolumn{1}{|c|}{ Property } & $\begin{array}{c}\text { Achieved with PPY in } \\
\text { Ionic Liquids }\end{array}$ & $\begin{array}{c}\text { Polypyrrole in 0.1 M } \\
\text { TEAP in PC }\end{array}$ & $\begin{array}{c}\text { Mammalian Skeletal } \\
\text { Muscle }\end{array}$ \\
\hline Displacement (Strain) & $14.5 \%$ (at $2.5 \mathrm{MPa})$ & $2 \%$ (at $10 \mathrm{MPa})$ & $20 \%$ \\
\hline Max. Active Stress (Load) & $>10 \mathrm{MPa}$ & $40 \mathrm{MPa}$ & $0.35 \mathrm{MPa}$ \\
\hline Velocity (Strain Rate) & $0.4 \% / \mathrm{s}($ at $5 \mathrm{MPa})$ & $3 \% / \mathrm{s}($ at $5 \mathrm{MPa})$ & $100 \% / \mathrm{s}$ \\
\hline Power to mass & $20 \mathrm{~W} / \mathrm{kg}$ & $150 \mathrm{~W} / \mathrm{kg}$ & $50-100 \mathrm{~W} / \mathrm{kg}$ \\
\hline Strain to charge & 1.7 to $8.8 \times 10^{-10} \mathrm{C} / \mathrm{m}^{3}$ & $1.3 \times 10^{-10} \mathrm{~m}^{3} / \mathrm{C}$ & - \\
\hline Efficiency & - & $0.6 \%($ at $4 \mathrm{MPa})$ & $30-35 \%$ \\
\hline Stiffness (wet) & $0.38 \mathrm{GPa}$ & 0.8 to $0.2 \mathrm{GPa}$ & 0.3 to $80 \mathrm{MPa}$ \\
(contracted)
\end{tabular}

${ }^{1}$ Hunter I. et. al., Technical Digest IEEE Solid State Sensors and Actuators Workshop, 1992.

${ }^{2}$ Madden et. al., in press.

Table 1: Comparison of polypyrrole actuators actuated in liquid salt with a similar polymer activated in PF6 based propylene carbonate solution.

\section{CONCULSION}

We presented herein electrical, electrochemical and mechanical (passive and active) characterizations performed on polypyrrole synthesized in $0.05 \mathrm{M}$ TEAP in propylene carbonate and activated in BMIM-BF4 ionic liquid. Activation of polypyrrole in ionic liquid resulted into unusual active behavior such as recoverable linear strains in excess of $14.5 \%$ against a load of $2.5 \mathrm{MPa}$ at a speed of $0.36 \% / \mathrm{s}$. These large however, strains are accompanied with a large creep, resulting in an average unrecoverable extension of the film by $3 \%$ per cycle. Further characterization and electrochemical modeling should lead to a better understanding of this system. Our overall goal is to find a single conducting polymer material that compares with or exceeds mammalian skeletal muscle properties in combined key figures of merit.

\section{ACKNOWLEDGEMENTS}

This work was supported in part by the Office of Naval Research under grant N00014-99-1-1022.

\section{REFERENCES}

1. Lu W., Fadeev A.G., Qi B., Smela E., Mattes B.R., Ding J., Spinks G.M., Mazurkiewicz J., Zhou D., Wallace G.G., MacFarlane D.R., Forsyth S.A. and Forsyth M., "Use of Ionic Liquids for pi-Conjugated Polymer Electrochemical Devices", Science, Vol. 297, pp. 983-987, (2002).

2. Spinks G.M., Liu L., Wallace G.G. and Zhou D., "Strain Response from Polypyrrole Actuators under Load", Advanced Functional Materials, Vol. 12, (6+7): pp. 437-440, (2002). 
3. Madden J.D., Madden P.G. and Hunter I.W., "Conducting Polymer Actuators as Engineering Materials", Smart Structures and Materials 2002: Electroactive Polymers Actuators and Devices, Yoseph Bar-Cohen, Editor, Proceedings of the SPIE, Vol. 4695, pp. 176-190, (2002).

4. Smela E, "Conjugated Polymer Actuators for Biomedical Applications", Advanced Materials, Vol. 15, (6): pp. 481-94, (2003).

5. Bay L., West K., Sommer-Larsen P., Skaarup S. and Benslimane M, "A conducting polymer artificial muscle with $12 \%$ linear strain", Advanced Materials, Vol. 15, (4): pp. 310-313, (2003).

6. Ding J., Liu L., Spinks G.M., Zhou D., Wallace G.G. and Gillespie J., "High Performance Conducting Polymer Actuators Utilizing a Tubular Geometry and Helical Wire Interconnects", Synthetic Metals, Vol. 9548, pp. 1-8, (2002).

7. Madden J.D., Madden P.G. and Hunter I.W., "Polypyrrole Actuators: Modeling and Performance", Smart Structures and Materials 2002: Electroactive Polymers Actuators and Devices, Yoseph Bar-Cohen, Editor, Proceedings of the SPIE, (2001).

8. Hunter I.W. and Lafontaine S., "A Comparison of Muscle with Artificial Actuators", Technical Digest IEEE Solid State Sensors and Actuators Workshop, pp. 178-185, (1992).

9. Marsella M.J. and Reid R.J., "Toward Molecular Muscles: Design and Synthesis of an Electrically Conducting Poly[cyclooctatetrathiophene]", Macromolecules, Vol. 32, pp. 5982-5984, (1999).

10. Jimenez M.C., Dietrich-Buchecker C. and Sauvage J.P., "Towards Synthetic Molecular Muscles: Contraction and Stretching of a Linear Rotaxane Dimer", Angewandte Chemie International, Vol. 39 No. 18, pp. 3284-3287, (2000).

11. Anquetil P.A., Yu H.-h., Madden J.D., Madden P.G., Swager T.M. and Hunter I.W., "Thiophene-Based Conducting Polymer Molecular Actuators", Smart Structures and Materials 2002: Electroactive Polymers Actuators and Devices, Yoseph Bar-Cohen, Editor, Proceedings of the SPIE, Vol. 4695, pp. 424-434, (2002).

12. Anquetil P.A., Yu H.-h., Madden J.D., Madden P.G., Swager T.M. and Hunter I.W., "Recent Progress in Thiophene-Based Conducting Polymer Molecular Actuators", Smart Structures and Materials 2003: Electroactive Polymers Actuators and Devices, Yoseph Bar-Cohen, Editor, Proceedings of the SPIE, (2003).

13. Pei Q. and Inganas O., "Electrochemical Application of the Bending Beam Method. 1. Mass Transport and Volume Changes in Polypyrrole during Redox", The Journal of Physical Chemistry, Vol. 96, (25): pp. 10507-10514, (1992).

14. Madden J.D., Cush R.A., Kanigan T.S. and Hunter I.W., "Fast Contracting Polypyrrole Actuators", Synthetic Metals, Vol. 113, pp. 185-192, (2000).

15. Lewis T.W., Spinks G.M., Wallace G.G., Mazzoldi A. and De Rossi D., "Investigation of the Applied Potential Limits for Polypyrrole when Employed as the Active Components in a Two-Electrode Device", Synthetic Metals, Vol. 122, (2): pp. 379385 , (2001).

16. Baughman R.H., Shacklette S.W., Plichta E.J. and Becht C., "Electromechanical Actuators Based on Conducting Polymers", Molecular Electronics, pp. 267-289, (1991).

17. Baughman R. H. "Conducting Polymer Artificial Muscles", Synthetic Metals, Vol. 78, pp. 339-353 , (1996).

18. Yamaura M Sato K and Iwata K, "Memory Effect of Electrical Conductivity Upon the Counter-Anion Exchange of Polypyrrole Films", Synthetic Metals, Vol. 48, (337-354): (1992).

19. Madden J.D., "Conducting Polymer Actuators", MIT PhD Thesis, (2000). 